\title{
Analytical Comparison of Structure with Reinforced Concrete Wall Against Lateral Load
}

\author{
${ }^{1}$ Prof. Mehul J. Bhavsar, ${ }^{2}$ Dr. Digant A. Pastagia \\ ${ }^{1,2}$ Assistant Professor, CED, SSASIT, Surat, Gujarat, India
}

\begin{abstract}
Buildings are generally designed to withstand against gravity load for expected life and resist extent of lateral loads by satisfying the codal provision. Main objective of structural elements is to transfer the load safely to the ground, which depends on structural system adopted. Generally, structural system can be adopted depending on the demand of client/building needs/use of structure, environmental condition, performance optimization, economic condition etc. For high rise building moment resisting frame system, structural wall systems, dual system, flat slab-structural wall systems can be employed. A residential ground with ten upper floors high rise building situated in zone-III has been taken under reference, where MRF with RC structural wall system is used. Structural parameters are compared in the study for various location and orientation of RC wall. Linear static and dynamic analysis is performed on the structure based on the IS 1893 Part-I on ETABS software.
\end{abstract}

Keywords : Structural system, high rise building, RC structural wall, IS 1893 part-I, ETABS

\section{INTRODUCTION}

Lateral loads like earthquake, wind etc. are most concerned for high rise structure. Moment resisting frame system is generally adopted in high rise buildings in addition of many lateral loads resisting elements like shear wall, bracings, core wall, outrigger and belt wall system etc. only MRF system for such structure is not efficiently work against earthquake and wind. In some region like southern part of India where probability of wind is more which creates more disaster while for northern part earthquake plays predominant role. So overall study of both probabilities is very important for structural engineer. Considering this, authors have adopted ground with ten upper storey structure of zone III for study with MRF and different location of RC wall.

\section{PROBLEM FORMULATION}

The residential building has taken for reference with following data;

- $\quad$ Structural system - MRF with RC wall

- Slab size-125 mm thick, Beam- 230x380 (green colour in plan and 230x450 (red colour in plan)

- Column-300x600 (brown colour in plan) and 300x750 (blue colour in plan)

- Floor finish- $1 \mathrm{kN} / \mathrm{m}^{2}$ on typical floor and 2 $\mathrm{kN} / \mathrm{m}^{2}$ on terrace

- Live load - $2 \mathrm{kN} / \mathrm{m}^{2}$

- Wall load-230 mm thick ACC block

- Soil type is medium.

- $\quad$ Storey height is $3.3 \mathrm{mt}$.

III. MODELLING

Building is modelled in structural software ETABS2017. Three models are prepared for study of various 
structural parameters. First model comprises of only MRF system (Refer fig. 1). Second and third model are prepared with MRF and RC wall at location shown in fig. 2 and 3 respectively. Earthquake and wind forces are applied as per respective codes. Load combinations as mentioned in IS 1893 are applied to model. Beam and column sizes are adopted based on experience. All joints are considered as rigid joints. Linear static and dynamic analysis is performed on all models.

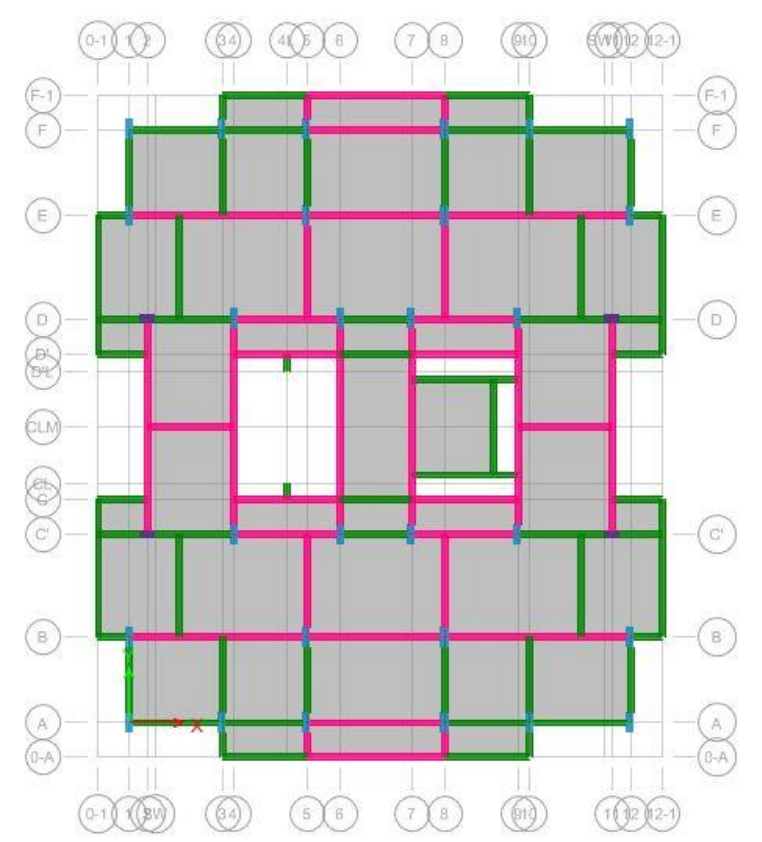

Fig. 1 Model -1;Plan without RC wall

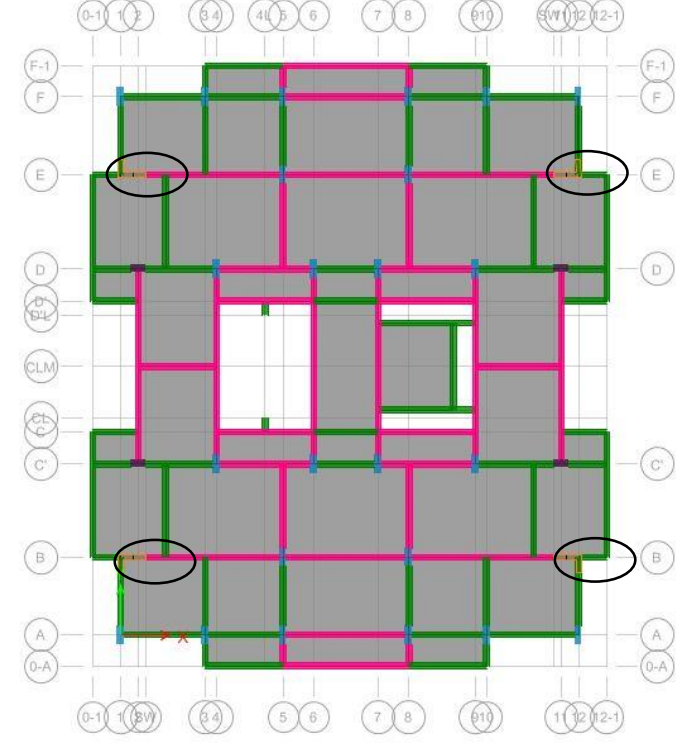

Fig. 2 plan of Model-2; cloud showing location of $\mathrm{RC}$ wall

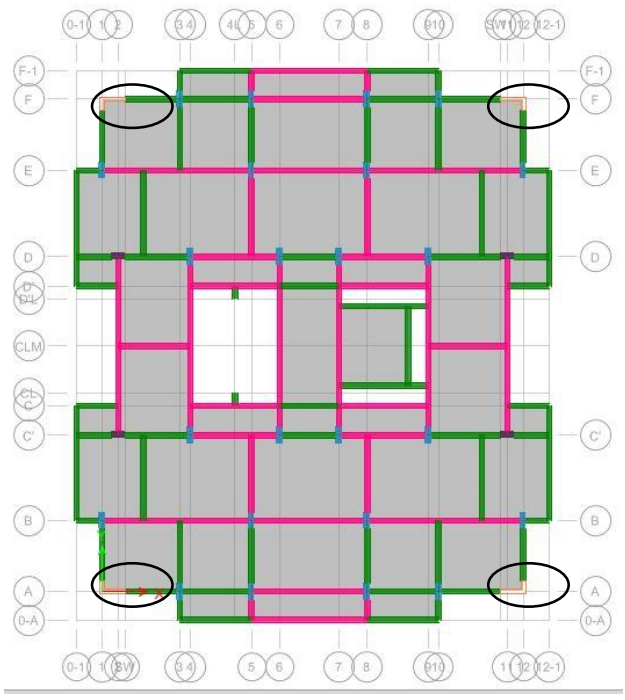

Fig 3 plan of Model-3; cloud showing location of $\mathrm{RC}$ wall

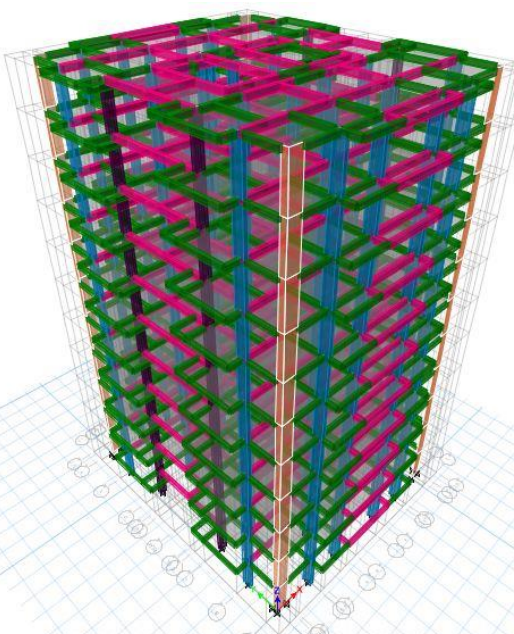

Fig 4 3D view of the model

\section{ANALYSIS AND RESULTS}

Structural parameters like deflections, base shear, drift, stiffness, modal participation, model mass etc are compared for all three models.

Deflection; for first model it is found that deflection in EQXP case (Earthquake in X positive direction) at top is $97.265 \mathrm{~mm}$. For second model it comes 89.908 $\mathrm{mm}$ and for third model it is $79.503 \mathrm{~mm}$. For first model it is found that deflection is EQYP case (Earthquake in Y positive direction) at top is 114.513 $\mathrm{mm}$. For second model it comes $110.633 \mathrm{~mm}$ and for 
third model it is $104.691 \mathrm{~mm}$. Graphical representation of maximum deflection of all floors is given below for EQXP and EQYP;
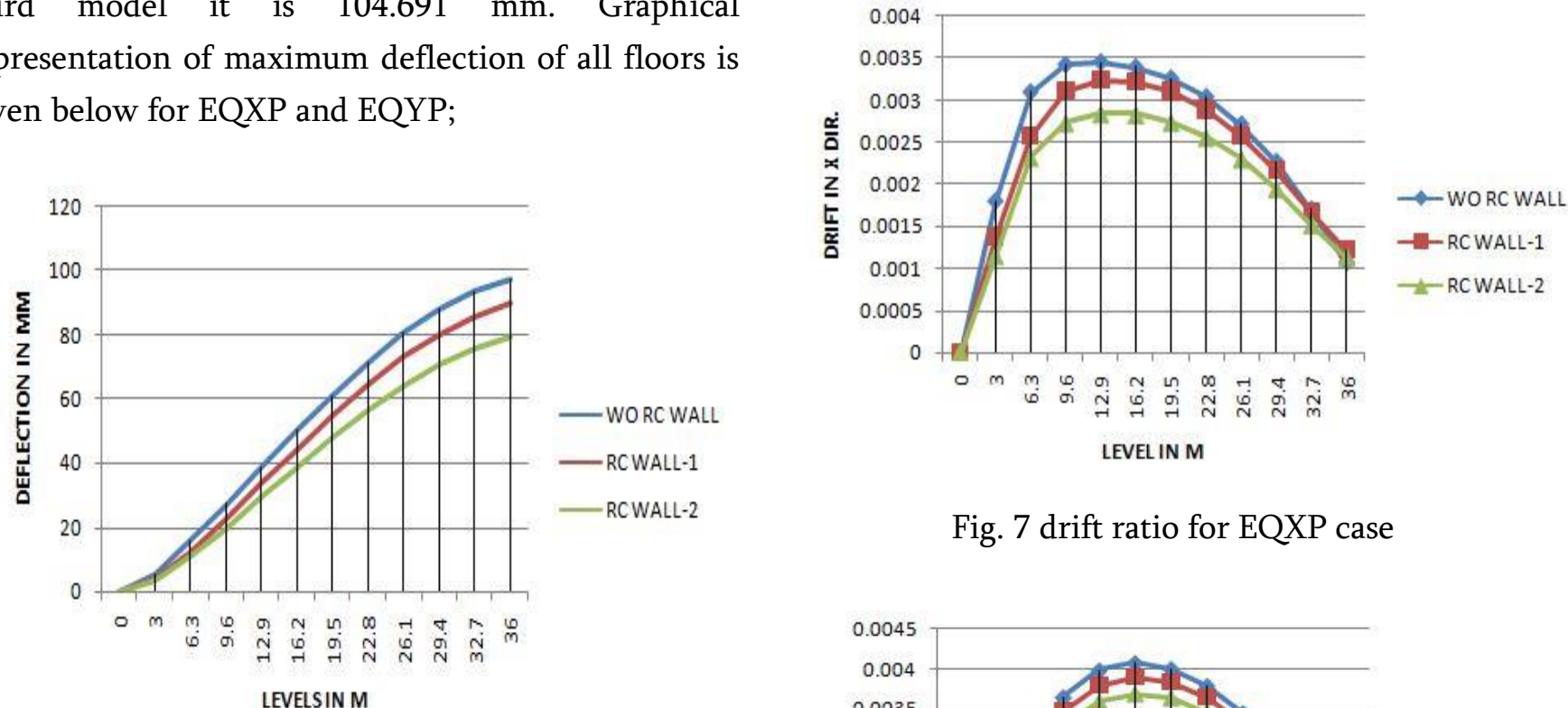

Fig. 7 drift ratio for EQXP case

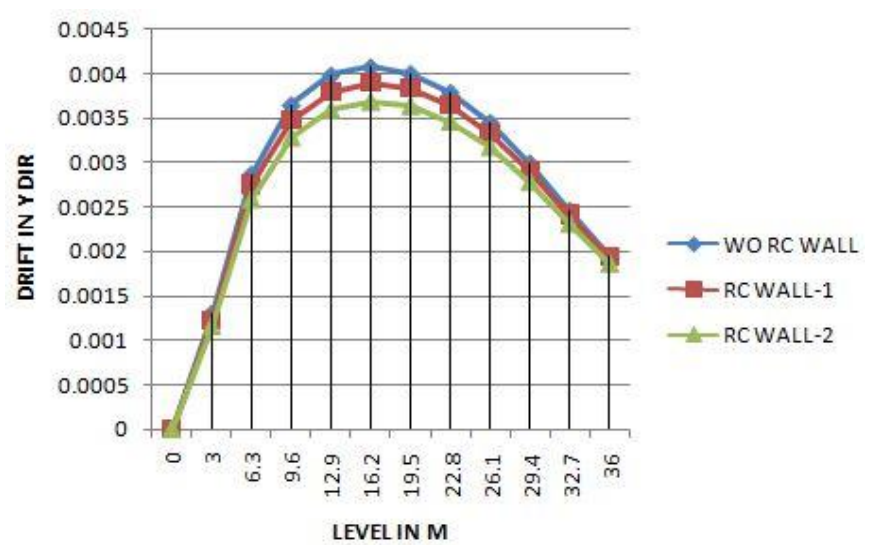

Fig. 8 drift ratio for EQYP case

Stiffness; Columns, beams and RC wall, if provided, contribute their stiffness to control deflection of the building. Stiffness of building as whole, considering geometry of the building, also contributes in controlling deflection. Earthquake in a particular direction induces shear at base, which is distributed along the height of structure at each floor level. For all three models these values are shown in fig. 9 and 10 for load case of EQXP and EQYP.

Drift; As per the IS 1893, maximum storey drift is 0.004 times height of storey. Figures underneath showing drift ratio for all three models for a case of EQXP and EQYP. 


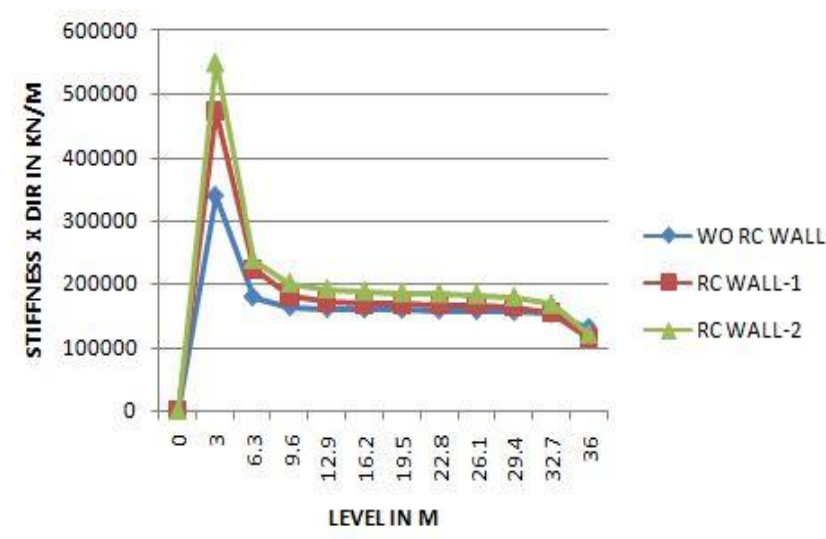

Fig. 9 storey stiffness in $\mathrm{x}$ direction

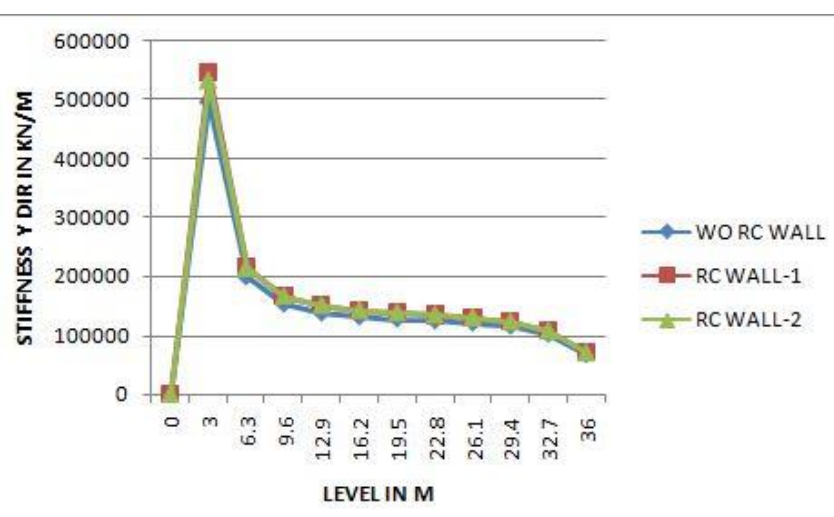

Fig. 10 storey stiffness in y direction

Model participation mass ratio; generally for building, initially horizontal force at base is calculated based on fundamental time period for a particular direction. In this study, result of first three modes is taken for study for all three models, which are tabulated as under.

Table 1: model participation mass ratio

\begin{tabular}{|c|c|c|c|c|}
\hline \multicolumn{5}{|c|}{ WO RC WALL } \\
\hline Mode & $\begin{array}{r}\text { Period } \\
\text { In sec }\end{array}$ & Ux & Uy & Rz \\
\hline 1 & 2.317 & 0 & 0.796 & 0 \\
\hline 2 & 2.205 & 0.844 & 0 & 0 \\
\hline 3 & 2.068 & 0 & 0 & 0.826 \\
\hline
\end{tabular}

Table 2: model participation mass ratio

\begin{tabular}{|c|c|c|c|c|}
\hline \multicolumn{5}{|c|}{ RC WALL-1 } \\
\hline Mode & $\begin{array}{c}\text { Period } \\
\text { In sec }\end{array}$ & $\mathrm{Ux}$ & $\mathrm{Uy}$ & $\mathrm{Rz}$ \\
\hline 1 & 2.241 & 0 & 0.772 & 0 \\
\hline 2 & 2.089 & 0.825 & 0 & 0 \\
\hline 3 & 2.003 & 0 & 0 & 0.821 \\
\hline
\end{tabular}

Table 3: model participation mass ratio

\begin{tabular}{|c|c|c|c|c|}
\hline \multicolumn{5}{|c|}{ RC WALL-2 } \\
\hline Mode & $\begin{array}{c}\text { Period } \\
\text { In sec }\end{array}$ & Ux & Uy & Rz \\
\hline 1 & 2.237 & 0 & 0.798 & 0 \\
\hline 2 & 1.982 & 0.824 & 0 & 0 \\
\hline 3 & 1.723 & 0 & 0 & 0.807 \\
\hline
\end{tabular}

\section{CONCLUDING REMARK}

It is sure that due to provision of structural wall many parameters get under controlled rather only with MRF system. But location of the wall plays a big role as far as analytical aspect is concern. In this study, $\mathrm{RC}$ wall is located at four location of the building and oriented in $\mathrm{X}$ direction majorly. It seems from the analytical results that deflection in EQXP is well controlled while in EQYP difference is very less. For a Storey drift, due to change of location of RC wall, the value of drift is drastically reduced for EQXP case while for EQYP effect is insignificant. For storey stiffness, though RC wall dimensions are not changed but due to the change of location of wall, stiffness for EQXP case gets increased, while for EQYP, wall is not contributing majorly in that direction, very negligible variation is observed. Regarding model participation mass ratio, without RC wall time period is 2.317, 2.205 and 2.068 with contribution of mass in respective direction. For MRF with RC wall with same mass of structure, these value get reduced as stiffness of the building is increased. 


\section{REFERENCES}

[1]. Shear wall design manual, computers and structures, CSI

[2]. Medhakar, M.S. and Jain, S.K., 1993, Seismic behaviour design and detailing of RC shear wall, part II: Designing and detailing, The Indian Concrete Journal.

[3]. Taranath, B.S., structural analysis and design of tall buildings (McGraw-Hill book company)

[4]. IS 1893-2002 and 2016 (part I), criteria for earthquake resistance design of structures, General provisions and buildings, BIS, New Delhi.

[5]. IS 456-2000, Plain and reinforced concrete, code of practice, BIS, New Delhi.

[6]. IS 13920-2016, Ductile Detailing of Reinforced concrete structures subjected to seismic forces, BIS, New Delhi.

\section{Cite this article as :}

Prof. Mehul J. Bhavsar, Dr. Digant A. Pastagia , "Analytical Comparison of Structure with Reinforced Concrete Wall Against Lateral Load", International Journal of Scientific Research in Computer Science, Engineering and Information Technology (IJSRCSEIT), ISSN : 2456-3307, Volume 5 Issue 2, pp. 1336-1340, March-April 2019. Available at doi : https://doi.org/10.32628/CSEIT2064122

Journal URL : https://ijsrcseit.com/CSEIT2064122 